\title{
Avaliação estrutural e distribuição espacial de Sideroxylon obtusifolium (Roem. \& Schult.) T. D. Penn. em sistema ecológico ciliar de riacho intermitente no Cariri paraibano
}

\section{Azenate Campos Gomes', Ana Paula de Souza Ferreira², Francisca Maria Barbosa ${ }^{3}$, Rui Oliveira Macêdo ${ }^{4}$ e Alecksandra Vieira de Lacerda ${ }^{5}$}

\begin{abstract}
${ }^{1}$ Universidade Federal da Paraíba. Programa de Pós-Graduação em Produtos Naturais e Sintéticos Bioativos. Campus I. João Pessoa-PB, Brasil (CEP 58037-275).

${ }^{2}$ Universidade Federal da Paraíba. Instituto de Pesquisa em Fármacos e Medicamentos (IPeFarM). Campus I. João Pessoa-PB, Brasil (CEP 58037-275).

${ }^{3}$ Pesquisadora Autônoma. Sumé-PB, Brasil (CEP 58540-000).

${ }^{4}$ Universidade Federal da Paraíba. Centro de Ciências da Saúde. Departamento de Ciências Farmacêuticas. Campus I. João Pessoa-PB, Brasil (CEP 58037-275).

${ }^{5}$ Universidade Federal de Campina Grande. Centro de Desenvolvimento Sustentável do Semiárido. Sumé-PB, Brasil (CEP 58540-000). E-mail: alecvieira@yahoo.com.br.
\end{abstract}

Resumo. Sideroxylon obtusifolium (Roem. \& Schult.) T. D. Penn. destaca-se pelo seu elevado potencial na Etnofarmacobotânica. Entretanto pouco se conhece sobre suas características ecológicas nos mais diferentes sistemas naturais pelos quais se distribui. 0 objetivo desse trabalho foi avaliar os dados estruturais e a distribuição espacial de $S$. obtusifolium em área de mata ciliar de caatinga conservada no cariri paraibano. 0 trabalho foi realizado no Riacho da Umburana $\left(7^{\circ} 45^{\prime} 15,3^{\prime \prime} \mathrm{S}\right.$ e $36^{\circ} 58^{\prime} 01,6^{\prime \prime} \mathrm{W} ; 571 \mathrm{~m}$ de altitude), localizado no Município de Sumé, na Microrregião do Cariri Ocidental Paraibano. Utilizou-se o método de parcelas contíguas de $10 \times 20 \mathrm{~m}$ para calcular a estrutura horizontal por meio dos valores relativos de densidade, frequência e dominância e os valores de importância e de cobertura, e para a estrutura vertical foram utilizadas diferentes classes de altura e diâmetro. Determinaram-se também os Índices de Diversidade de Shannon e de Equabilidade de Pielou para a comunidade estudada. A maior parte das parcelas apresenta apenas um indivíduo da espécie estudada. A maior contribuição de $S$. obtusifolium para a comunidade estudada está na dominância relativa $(5,07 \%)$, valor justificável pelo significativo diâmetro de alguns espécimes, resultando em uma área basal e consequentemente dominância relativa mais significativa dentro da comunidade. Tanto para o parâmetro altura como diâmetro, a segunda classe $(3,1$ a 5,0 m de altura e 4,1 a 5,0 cm de diâmetro) deteve o maior número de indivíduos, indicando maior representatividade nas classes mais

Recebido $15 / 12 / 2019$

Aceito

$27 / 02 / 2020$

Disponível on line $08 / 03 / 2020$

Publicado $30 / 04 / 2020$

Acesso aberto

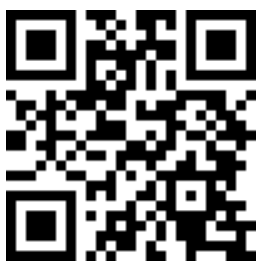

ISSN 2359-1412/RBGAS-2019-0106/2020/7/15/2/21

Rev. Bras. Gest. Amb. Sustent.

http://revista.ecogestaobrasil.net 
próximas ao limite mínimo estabelecido para caracterização de indivíduos adultos. Portanto, os dados ofertam subsídios para a compreensão do comportamento estrutural da espécie estudada, demonstrando a sua contribuição ecológica dentro de sistemas naturais ribeirinhos no Semiárido e auxiliando no manejo e conservação da espécie.

Palavras-chave: Estrutura da vegetação; Quixabeira; Mata ciliar; Caatinga.

Abstract. Structural assessment and space distribution of Sideroxylon obtusifolium (Roem. \& Schult.) T. D. Penn. in an intermittent stream riparian ecological system in the Cariri paraibano, Northeast Brazil. Sideroxylon obtusifolium (Roem. \& Schult.) T. D. Penn. stands out for its high potential in Ethnopharmacobotany. However, its ecological characteristics in the most different natural systems to which it is distributed are little known. Thus, this study aimed to evaluate the structural data and the spatial distribution of $S$. obtusifolium in a preserved riparian forest area in the Caatinga, in the "Cariri Paraibano" Region. This research was carried out in the "Umburana" Stream ( $7^{\circ} 45^{\prime} 15.3^{\prime \prime} \mathrm{S}$ and $36^{\circ} 58^{\prime} 01.6^{\prime \prime} \mathrm{W} ; 571 \mathrm{~m}$ altitude), located in the Municipality of Sumé in the "Cariri Ocidental Paraibano" Microregion. Contiguous plots of $10 \times 20 \mathrm{~m}$ were used to calculate the horizontal structure using relative values of density, frequency, and dominance, as well as the importance and coverage values. For the vertical structure, different height classes and diameter were used. Shannon Diversity and Pielou Equability Indices were also determined for the study community. The relative dominance $(5.07 \%)$ is the major contribution of $S$. obtusifolium to the study community. This value is justified by the significant diameter of some specimens, resulting in a basal area and consequently in a relative dominance more significant within the community. For both height and diameter, the second class (3.1 to $5.0 \mathrm{~m}$ in height and 4.1 to $5.0 \mathrm{~cm}$ in diameter) encompassed the largest number of specimens, indicating greater representativeness in the classes closer to the minimum limit established for characterization of adult individuals. Most plots had only one specimen. Therefore, these data provide support for understanding the structural behavior of S. obtusifolium, demonstrating its ecological contribution within natural riparian systems in semi-arid regions and assisting in the management and conservation of this species.

Keywords: Vegetation structure; Quixabeira; Riparian forest; Caatinga.

\section{Introdução}

O Semiárido brasileiro é caracterizado por apresentar um clima com sistema de chuvas extremamente irregular em sua distribuição anual, com variação média de desvio de $20 \%$ até mais de $50 \%$. Esta região possui o maior índice pluviométrico dentre as

\footnotetext{
(D) 0000-0001-6184-3114

Azenate Campos

Gomes

(1) 0000-0003-4983-3305

Ana Paula de Souza

Ferreira

(D) 0000-0002-6273-0979

Francisca Maria

Barbosa

D) 0000-0003-2942-9284

Rui Oliveira Macêdo

(D) 0000-0002-9703-3997

Alecksandra Vieira de

Lacerda
} 
regiões semiáridas do mundo (Prado, 2003), logo, o conhecimento do sincronismo e da amplitude das chuvas vem a ser fundamental para o estudo da dinâmica dos ecossistemas presentes nessa região. 0 bioma Caatinga é predominante nessa região, ocupando cerca de $11 \%$ do país, e caracteriza-se principalmente por ser considerado exclusivamente brasileiro. Entretanto, é o ecossistema menos conhecido da América do Sul, tendo em vista, o pequeno número de pesquisas realizadas no mesmo, decorrente da sua desvalorização (MMA, 2010).

No Semiárido, as matas ciliares da região foram os primeiros locais a sofrer alteração na vegetação por serem áreas preferenciais para o cultivo agrícola no período colonial, de forma que, até hoje esse recurso natural é explorado inadequadamente (Souza e Rodal, 2010), embora sejam áreas de preservação permanente (APPs) protegida pela Lei no 12.651/2012, o código Florestal Brasileiro (Brasil, 2012). Estes ambientes são extremamente importantes no que tange aos seus aspectos funcionais, ao passo que, são responsáveis pelo equilibro ecológico dos ecossistemas, assumindo uma função protetora estabelecendo interações que se estendem, a partir das margens, por vários metros a depender das características estruturais destes ecossistemas (Lacerda e Barbosa, 2018; Lacerda et al., 2010).

Conforme Martins et al. (2017), estudar a dinâmica de uma floresta é imprescindível para conhecer o comportamento da mesma, nos diferentes estágios de sucessão, sendo feito assim, um aproveitamento racional e garantindo a sobrevivência das florestas naturais. Para isto, é necessário a aplicação de técnicas silviculturais adequadas, baseadas na ecologia de cada tipologia florestal. A aplicação de técnicas corretas de manejo florestal, deve tomar como base, o conhecimento sobre a sua composição e estrutura. Para Lacerda e Barbosa (2018) estudos gerados a partir de dados estruturais em matas ciliares no Semiárido brasileiro são importantes ferramentas na proposição de estratégias de conservação e restauração dos seus ecossistemas ribeirinhos que possui um histórico de degradação secular, o qual vem se intensificando cada vez mais.

Dentre as espécies de ocorrência na Caatinga, Sideroxylon obtusifolium (Roem. \& Schult.) T. D. Penn. (Sapotaceae), destaca-se pelo seu elevado potencial socioeconômico e ambiental (Aquino et al., 2016; Albuquerque e Hanazaki, 2006; Maia, 2004), entretanto, pouco se conhece sobre o comportamento e a ecologia desta espécie em sistemas conservados de caatinga, informações essas que poderiam auxiliar muito em estratégias de manejo e conservação desta espécie de elevado potencial na região.

O objetivo desse trabalho foi avaliar os dados estruturais e a distribuição espacial de S. obtusifolium em área de mata ciliar de caatinga conservada no cariri paraibano.

\section{Material e métodos}

\section{Área de estudo}

O trabalho foi realizado no Município de Sumé, na Microrregião do Cariri Ocidental Paraibano. De acordo com a classificação de Köppen (Alvares et al., 2014), o clima da região é do tipo climático BSh, ou seja, seco (Semiárido). A estação chuvosa concentra-se em três meses do ano, com precipitação anual média de $590 \mathrm{~mm}$. A temperatura média anual é de $24{ }^{\circ} \mathrm{C}$, a insolação anual média é de $2.800 \mathrm{~h}$ e a evaporação anual média no tanque classe A é de $2.900 \mathrm{~mm}$. O solo predominante é o Luvissolo, representativo da zona semiárida, com permeabilidade lenta, com profundidade em torno de $0,5 \mathrm{~m}$ a $1,0 \mathrm{~m}$ e em muitos locais ocorre afloramento de rocha. 0 relevo é de pouco ondulado a ondulado (Srinivasan et al., 2003).

Neste município a área ciliar estudada se definiu pelas seguintes características: remanescente com um significativo grau de conservação servindo os aspectos estruturais e funcionais que marcam este ecossistema de modelo, para indicar, estruturar e adequar às propostas de conservação e recuperação de ambientes perturbados. Assim caracterizado, o 
Riacho da Umburana $\left(7^{\circ} 45^{\prime} 15,3^{\prime \prime} \mathrm{S}\right.$ e $36^{\circ} 58^{\prime} 01,6^{\prime \prime} \mathrm{W}$; $571 \mathrm{~m}$ de altitude), tem sua nascente localizada no Sítio Boa Esperança, Município de Monteiro-PB e desemboca no Açude Jatobá, em Sumé. 0 trecho amostrado do riacho neste estudo está definido dentro dos limites da Fazenda Nova.
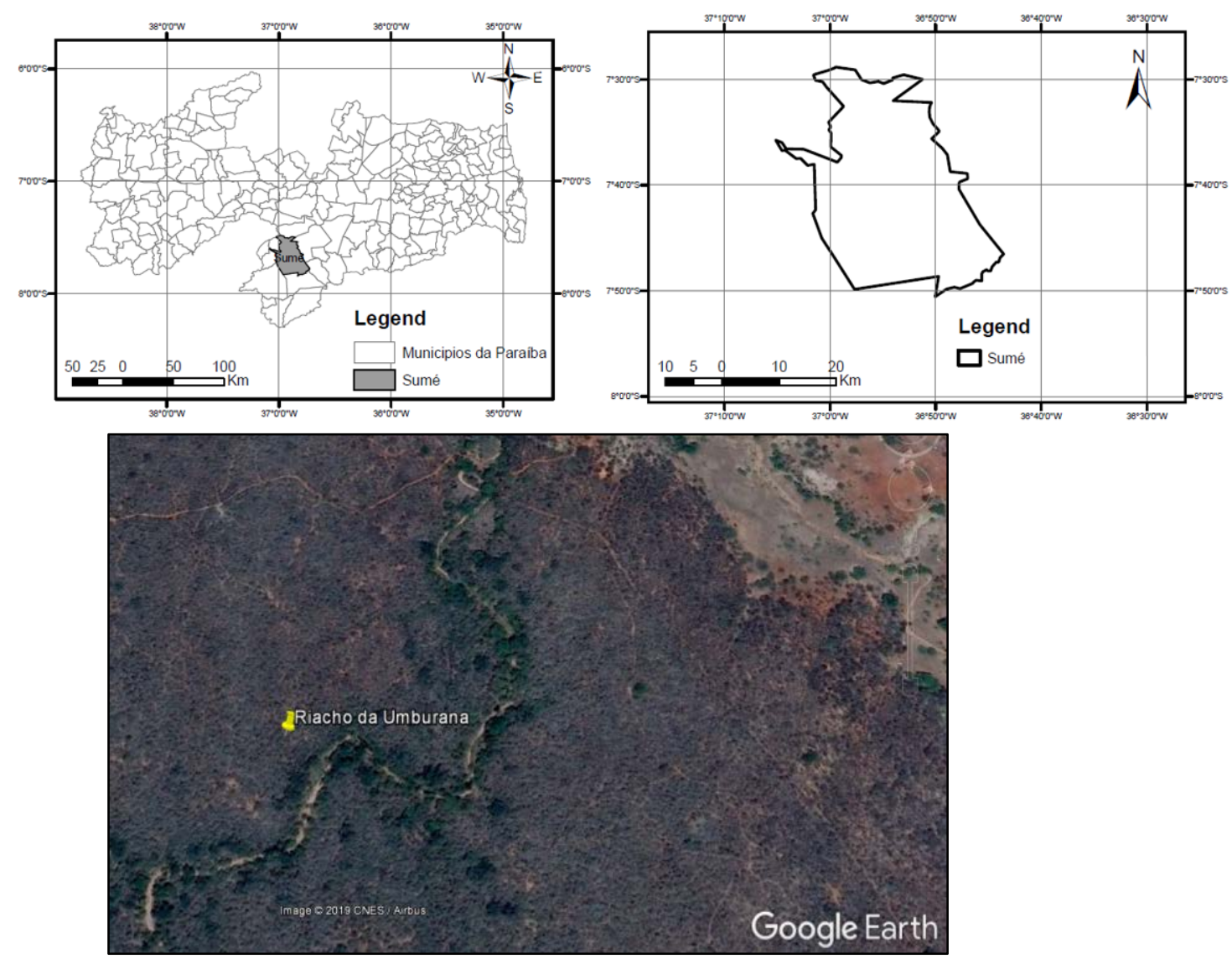

Figura 1. Riacho da Umburana no município de Sumé no Cariri Ocidental paraibano

\section{Coleta e análise dos dados}

Para a avaliação dos parâmetros estruturais da vegetação, foi utilizado o método de parcelas contíguas (Mueller-Dombois e Ellemberg, 1974). Foram dispostas 51 parcelas contíguas de $10 \times 20 \mathrm{~m}$, distribuídas em três faixas paralelas ao longo da margem esquerda do curso d'água. Os critérios de inclusão utilizados foram amostrar os indivíduos arbustivo-arbóreos, vivos e mortos ainda em pé, com diâmetro do caule ao nível do solo (DNS) $\geq 3 \mathrm{~cm}$ e altura total $\geq 1 \mathrm{~m}$. Os indivíduos foram marcados com plaquetas, numerados e identificados pelo nome científico, e quando não identificados, foram coletados para posterior identificação. Foram medidos os perímetros ao nível do solo, com fita métrica e posteriormente convertidos em diâmetro. Para as árvores e arbustos com troncos múltiplos foram medidos todos os ramos com DNS $\geq 3 \mathrm{~cm}$. A altura dos indivíduos foi determinada com auxílio de uma vara de $4 \mathrm{~m}$. Para indivíduos mais altos, foram feitas estimativas por comparação com esta vara.

Os dados obtidos em campo foram manipulados em planilha eletrônica Microsoft Excel versão 2010, para a caracterização da densidade, frequência e dominância da 
espécie (Mueller-Dombois e Ellenberg, 1974). A partir dos parâmetros relativos, foram calculados o valor de importância (VI) e o valor de cobertura (VC). Foram elaborados histogramas de distribuição de frequência de classes de altura e diâmetro com intervalos de $3 \mathrm{~cm}$ e $2 \mathrm{~m}$ de todos os indivíduos amostrados respectivamente. Determinaram-se também os Índices de Diversidade de Shannon e de Equabilidade de Pielou para a comunidade estudada.

\section{Resultados e discussão}

Considerando as 51 parcelas estudadas, S. obtusifolium ocorreu em 16, ou seja em $31,4 \%$ das parcelas. 0 maior número de indivíduos (10) esteve distribuído ao longo de diferentes parcelas, as quais encontram-se localizadas em sua grande maioria entre os primeiros $20 \mathrm{~m}$ a partir da margem do riacho. Isso indica que considerando-se uma área de $10 \times 20 \mathrm{~m}$, a maior parte das parcelas suportam apenas um indivíduo da espécie estudada. Duas parcelas apresentam mais de duas espécimes, são elas, as parcelas 3 e 4 representadas por quatro e três indivíduos respectivamente (Figura 2).

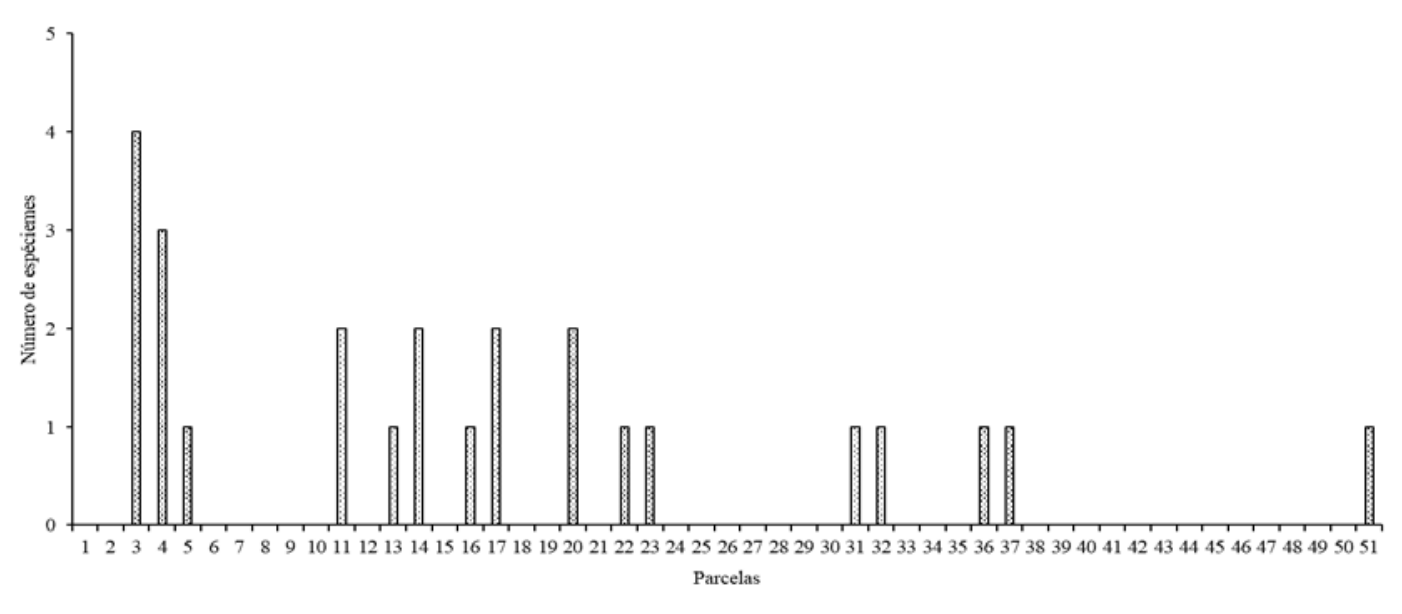

Figura 2. Distribuição por parcela de espécimes de S. obtusifolium em área ribeirinha do Riacho da Umburana no Município de Sumé, Cariri ocidental paraibano.

Dentre os fatores ambientais, o substrato é um dos mais importantes na determinação da estruturação espacial das populações vegetais (Mueller-Dombois e Ellenberg, 1974). De acordo com Haridasan (2005) a heterogeneidade das condições edáficas como idade, textura, profundidade, fertilidade e disponibilidade hídrica do solo são produtos das variações fitofisionômicas de Biomas e influenciam diretamente na distribuição geográfica de algumas espécies vegetais. Entretanto, é importante ressaltar a heterogeneidade local, a qual está diretamente ligada a distribuição espacial dos indivíduos em escalas menores a exemplo de populações como S. obtusifolium, uma vez que o estabelecimento das plantas ocorre conforme as características do substrato propícias ao seu desenvolvimento. Barbour et al. (1987) afirma que caso o solo de uma região apresente manchas locais com diferentes características físicas e químicas, as populações vegetais tendem a se estruturar da mesma maneira, apresentando, portanto, indivíduos agregados no espaço. Dentre as questões físicas que influenciam o tipo de distribuição dos indivíduos tem-se os ambientes de maior umidade, a exemplo das faixas 
de solos mais próximas a margem do riacho que influenciou positivamente da ocorrência das espécimes.

A estrutura horizontal representada pela densidade relativa (DR), frequência relativa (FR), dominância relativa (DoR), valor de importância (VI) e valor de cobertura (VC), mostraram que a maior contribuição de $S$. obtusifolium para a comunidade estudada está na dominância relativa $(5,07 \%)$, valor justificável pelo significativo diâmetro de algumas espécimes, resultando em uma área basal e consequentemente dominância relativa mais significativa dentro da comunidade. A segunda maior contribuição da espécie para a comunidade estudada foi o valor de cobertura (2,83\%), uma vez que no seu cálculo está englobado a dominância relativa que foi bastante expressiva (Figura 3). Na Comunidade do Riacho da Umburana S. obtusifolium ocupou a décima quinta posição considerando o parâmetro valor de importância que foi de $2,60 \%$.

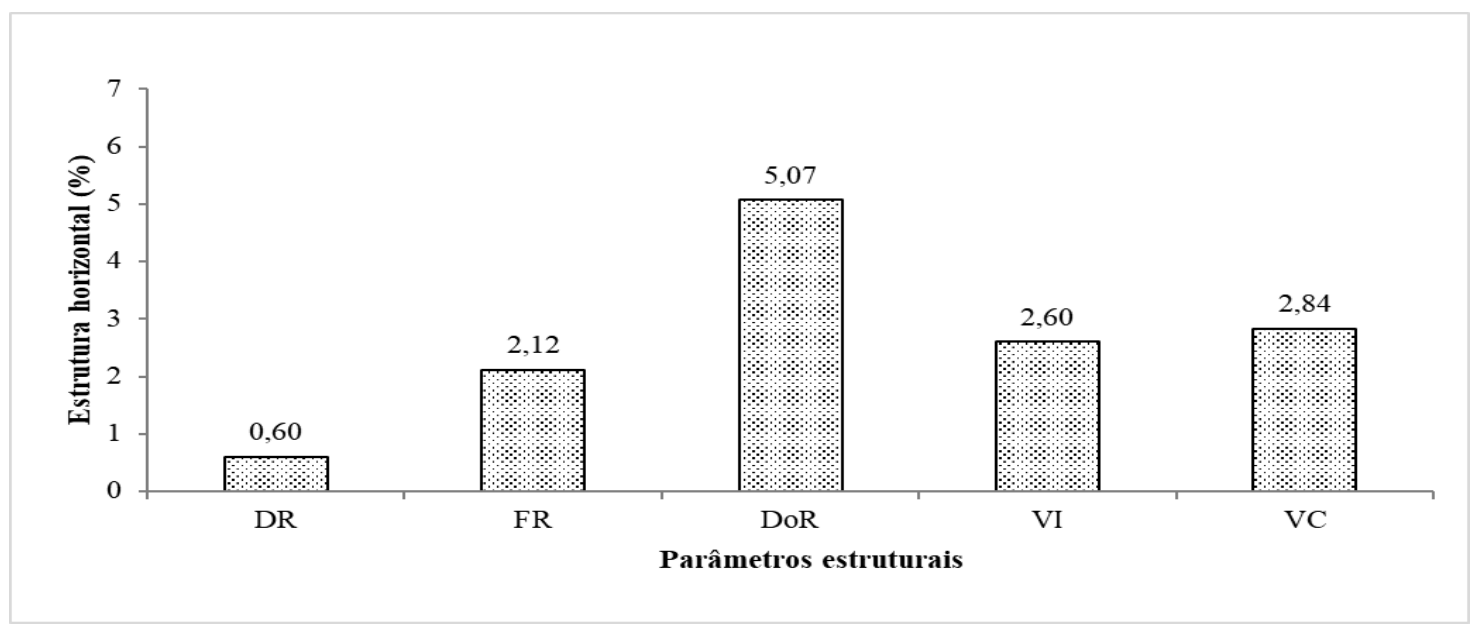

Figura 3. Estrutura horizontal de S. obtusifolium em relação à comunidade vegetal do Riacho da Umburana no Município de Sumé, Cariri ocidental paraibano. DR: Densidade relativa; FR: frequência reativa; DoR: dominância relativa; VI: Valor de importância; VC: valor de cobertura.

Os resultados encontrados foram semelhantes aos de Lacerda e Barbosa (2018) no Riacho Farias, localizado também no Semiárido Paraibano, as quais registraram valor de importância e de cobertura para S. obtusifolium de 7,64 (2,54\%) e 6,38 (3,19\%) respectivamente, destacando-se também pelos seus valores de dominância relativa.

A distribuição de S. obtusifolium ao longo da área estudada associada a dominância relativa corrobora com o padrão citado por Lamprecht, (1990) ao afirmar que a baixa densidade e elevados valores de frequência e dominância é a condição típica para árvores dominantes isoladas e em número reduzido, porém dispersas com certa regularidade por áreas relativamente grandes.

S. obtusifolium caracterizou-se na comunidade estudada dentro de 5 classes de altura, onde a segunda classe que refere-se ao intervalo de 3,1 a $5,0 \mathrm{~m}$ foi a mais representativa com 12 espécimes, seguido pela primeira e terceira classe que correspondem ao intervalo de 1,0 a 3,0 e 5,1 a 7,0 m respectivamente, estando cada uma representada por 5 espécimes. As demais classes foram representadas por no máximo dois indivíduos (Figura 4A). Relacionado ao diâmetro, observou-se um elevado número de classes (61), mas apenas 13 obtiveram espécimes, sendo a segunda classe a mais representativa com intervalo entre 4,1 e $5,0 \mathrm{~cm}$ com 6 indivíduos, seguido pela terceira 
classe que corresponde a 5,1 a 6,0 $\mathrm{cm}$ com 5 indivíduos, a primeira classe $(3,0$ a 4,0 cm) com 4 e a quarta classe $(6,1$ a 7,0$)$ com dois indivíduos. As demais classes com registro de espécimes, obtiveram apenas 1 representante. Vale destacar que no intervalo de 23 e $56,1 \mathrm{~cm}$ não houve registro de nenhum indivíduo, sendo este o maior espaço sem representação de classe diamétrica de S. obtusifolium na área estudada (Figura 4B). De modo geral tanto para o parâmetro altura como diâmetro, a segunda classe detém o maior número de indivíduos, indicando maior representatividade nas classes mais próximas ao limite mínimo estabelecido para caracterização de indivíduos adultos, sugerindo que esta população tem uma grande contribuição de adultos jovens para a comunidade vegetal do riacho da Umburana.

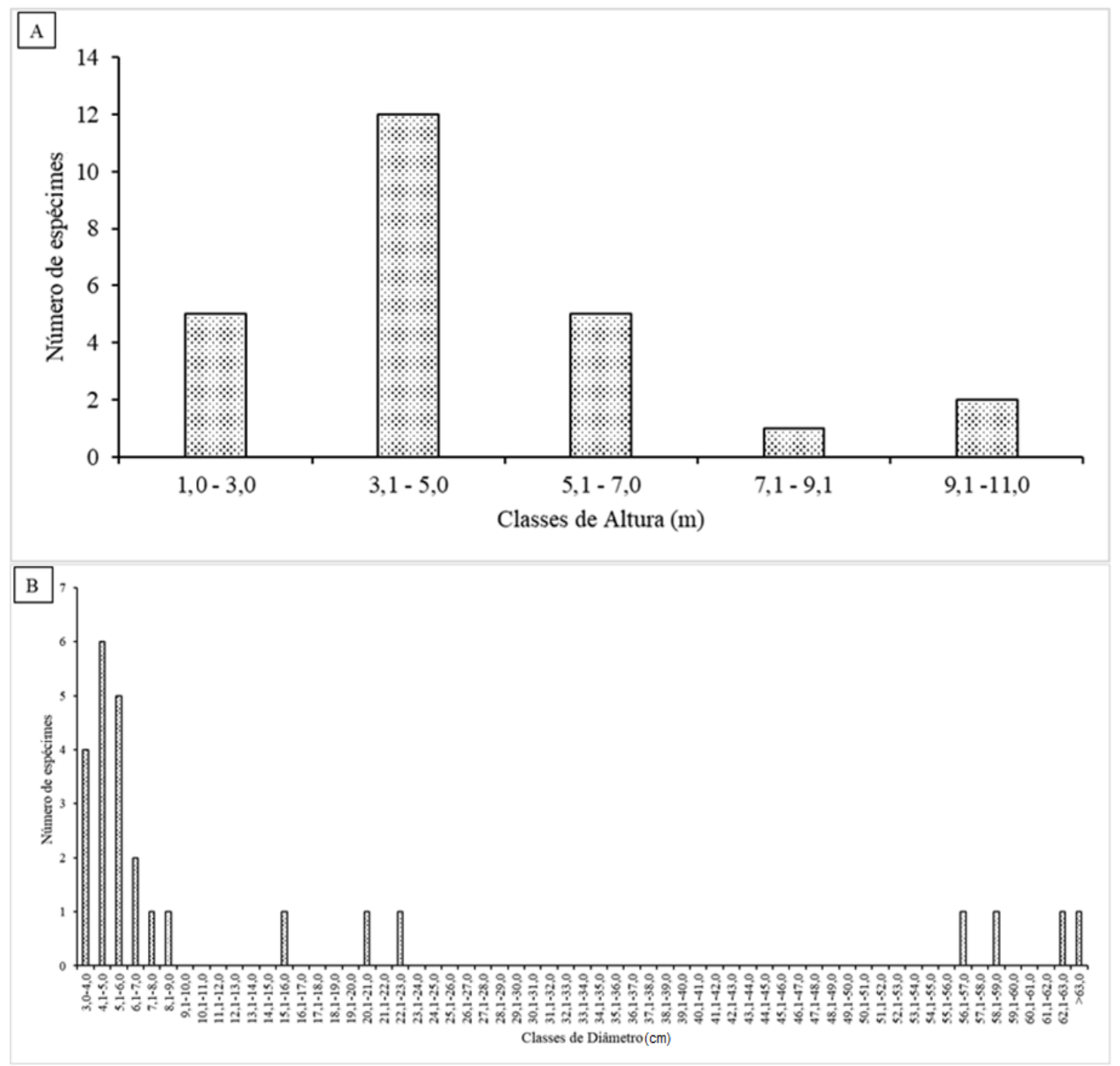

Figura 4. Distribuição por classe de altura (A) e diâmetro (B) de espécimes de S. obtusifolium em área ribeirinha do riacho da Umburana no município de Sumé, Cariri Ocidental paraibano.

Relacionado ao diâmetro, a maior representação de espécimes que vai até $9,0 \mathrm{~cm}$ forma o J invertido, indicando um número decrescente de árvores à medida que se 
aumenta o diâmetro. Este padrão de distribuição também foi encontrado por Martins et al. (2017) estudando Floresta Ombrófila Mista Montana. Segundo esses autores o J invertido é característico das florestas multiâneas, onde não existe uniformidade dos indivíduos e não se sabe a idade das árvores, as quais se encontram também em vários estágios de regeneração (Lima e Leão, 2013).

A diversidade do Riacho da Umburana caracterizou-se por índice de diversidade e equabilidade de 2,67 nats.ind. ${ }^{-1}$ e 0,70 respectivamente, configurando-se como área de mata ciliar de caatinga conservada. Farias et al. (2017) em seu trabalho nesta área ciliar também ressaltou os níveis de conservação pelos dados registrados. Assim, observou-se que esta característica contribui para que os valores de estrutura horizontal de S. obtusifolium não sejam tão altos, uma vez que cada espécie terá a sua contribuição dentro de um padrão de uniformidade considerável para a comunidade vegetal.

\section{Conclusões}

Portanto, observou-se em relação aos parâmetros de estrutura horizontal a maior contribuição de $S$. obtusifolium para a comunidade vegetal estudada foi dominância relativa $(5,07 \%)$, devido o significativo diâmetro de alguns espécimes, resultado de uma área basal bastante expressiva, seguido pelo valor de cobertura $(2,84 \%)$. Registrou-se que a maior representatividade de altura e diâmetro de S. obtusifolim encontra-se na segunda classe, indicando maior número de espécimes nas classes mais próximas ao limite mínimo estabelecido para caracterização de indivíduos adultos, sugerindo que esta população tem uma grande contribuição de adultos jovens para a comunidade vegetal do riacho da Umburana. Os dados gerados auxiliam na compreensão do comportamento estrutural desta espécie e na sua contribuição ecológica dentro de comunidades vegetais ribeirinhas no Semiárido brasileiro.

\section{Agradecimentos}

Ao CNPq pelo financiamento da pesquisa, a família Mayer, proprietários da Fazenda Nova, e aos integrantes do Laboratório de Ecologia e Botânica, do Centro de Desenvolvimento Sustentável do Semiárido, da Universidade Federal de Campina Grande.

\section{Conflito de Interesses}

Os autores declaram não haver conflitos de interesses.

\section{Referências}

Albuquerque, U. P.; Hanazaki, N. As pesquisas etnodirigidas na descoberta de novos fármacos de interesse médico e farmacêutico: fragilidades e perspectivas. Revista Brasileira de Farmacognosia, v. 16, Supl., p.678-689, 2006. https://doi.org/10.1590/ S0102-695X2006000500015

Alvares, C. A.; Stape, J. L.; Sentelhas, P. C.; Gonçalves, J. L. M.; Sparovek, G. Köppen’s climate classification map for Brazil. Meteorologische Zeitschrift, v. 22, n. 6, p. 711-728, 2014. https://doi.org/10.1127/0941-2948/2013/0507

Aquino, P.; Figueredo, F. G.; Pereira, N.; Nascimento, E.; Martin, A.; Veras, H.; Oliveira, C.; Ferreira, S.; Leandro, L.; Silva, M.; Menezes, I. Evaluation of the topical anti-inflammatory activity and antibacterial activity of methanol extract in the Sideroxylon obtusifolium leaves. Acta Biológica Colombiana, v. 21, n. 1, p. 131-140, 2016. 
Barbour, M. G.; Burk, J. H.; Pitts, W. D. Terrestrial plant ecology. 2. ed. Menlo-Park: Benjamim/Cummings, 1987.

Brasil. Lei no 12.651, de 25 de maio de 2012. Dispõe sobre a proteção da vegetação nativa; altera as Leis $\mathrm{n}^{\mathrm{os}}$ 6.938, de 31 de agosto de 1981, 9.393, de 19 de dezembro de 1996, e 11.428, de 22 de dezembro de 2006; revoga as Leis nos 4.771, de 15 de setembro de 1965, e 7.754, de 14 de abril de 1989, e a Medida Provisória no 2.166-67, de 24 de agosto de 2001; e dá outras providências. Disponível em: <http://www.planalto.gov.br/ ccivil_03/_ato2011-2014/2012/lei/l12651.htm>. Acesso em: 15 jul. 2019.

Farias R. C.; Lacerda, A. V.; Gomes, A. C.; Barbosa, F. M.; Dornelas, C. S. Riqueza florística em uma área ciliar de Caatinga no Cariri Ocidental da Paraíba, Brasil. Revista Brasileira de Gestão Ambiental e Sustentabilidade, v. 4, n. 7, p.109-118, 2017. https://doi.org/10.21438/rbgas.040711

Haridasan, M. Competição por nutrientes em espécies arbóreas do cerrado. In: Silva J. C. S.; Felfili, J. M. (Orgs.). Cerrado: Ecologia, biodiversidade e conservação. Brasília: Ministério do Meio Ambiente, 2005. p. 73-92.

Lacerda, A. V.; Barbosa, F. M. Fitossociologia da vegetação arbustivo-arbórea em uma área de mata ciliar no semiárido paraibano, Brasil. Gaia Scientia, v. 12, n. 2, p. 34-43, 2018. https://doi.org/10.22478/ufpb.1981-1268.2018v12n2.35719

Lacerda, A. V.; Barbosa, F. M.; Soares, J. J.; Barbosa, M. R. V. Flora arbustiva-arbórea de três áreas ribeirinhas no semiárido paraibano, Brasil. Biota Neotropica, v. 10, n. 4, p. 275-284, 2010. https://doi.org/10.1590/S1676-06032010000400032

Lamprecht, H. Silvicultura nos trópicos: ecossistemas florestais e respectivas espécies arbóreas - possibilidades e métodos de aproveitamento sustentado. Rossdorf: República Federal da Alemanha: Dt. Ges. für Techn. Zusammenarbeit, 1990.

Lima, J.P. C.; Leão, J.R.A. Dinâmica de crescimento e distribuição diamétrica de fragmentos de florestas nativa e plantada na Amazônia Sul Ocidental. Floresta e Ambiente, v. 20, n. 1, p. 70-79, 2013. https://doi.org/10.4322/floram.2012.065

Maia, G. N. Caatinga: árvores e arbustos e suas utilidades. 1. ed. São Paulo: Leitura e Arte, 2004.

Martins, P. J.; Mazon, J. A.; Martinkoski, L.; Benin, C. C.; Watzlawick, L. F. Dinâmica da vegetação arbórea em Floresta Ombrófila Mista Montana Antropizada. Floresta e Ambiente, v. 24, p. 1-12, 2017. https://doi.org/10.1590/2179-8087.097014

MMA - Ministério do Meio Ambiente. Caatinga: contexto, características e estratégias de conservação. 2010. Disponível em: <http://www.mma.gov.br/biomas/caatinga/ item/191>. Acesso em: 15 jul. 2019.

Mueller-Dombois D.; Ellenberg, H. Aims and methods of vegetation ecology. New York: John Willey e Sons, 1974.

Prado, D. E. As caatingas da América do Sul. In: Leal, I. R.; Tabarelli, M.; Silva, J. M. C. (Eds.). Ecologia e conservação da Caatinga. Recife: Editora Universitária da UFPE, 2003. p. 3-73.

Souza, J. A. N.; Rodal, M. J. N. Levantamento florístico em trecho de vegetação ripária de caatinga no Rio Pajeú, Floresta/Pernambuco-Brasil. Revista Caatinga, v. 23, n. 4, p. 54-62, 2010. 
Srinivasan, V. S.; Santos, C. A.; Galvão, G. C. O. Erosão hídrica do solo no semi-árido brasileiro: a experiência na Bacia Experimental de Sumé. RBRH - Revista Brasileira de Recursos Hídricos, v. 8, n. 2, p. 57-73, 2003. https://doi.org/10.21168/rbrh.v8n2.p57-73 